\title{
(6) OPEN ACCESS \\ Short-term changes in quitting-related cognitions and behaviours after the implementation of plain packaging with larger health warnings: findings from a national cohort study with Australian adult smokers
}

\author{
Sarah Durkin, Emily Brennan, Kerri Coomber, Meghan Zacher, Michelle Scollo, \\ Melanie Wakefield
}

- Additional material is published online only. To view please visit the journal online (http://dx.doi.org/10.1136/ tobaccocontrol-2014-052058)

Centre for Behavioural Research in Cancer, Cancer Council Victoria, Melbourne, Victoria, Australia

\section{Correspondence to} Professor Melanie Wakefield Centre for Behavioural Research in Cancer, Cancer Council Victoria, 615 St Kilda Rd, Melbourne, VIC 3004, Australia; melanie.wakefield@ cancervic.org.au

Received 25 September 2014 Revised 12 December 2014 Accepted 13 January 2015

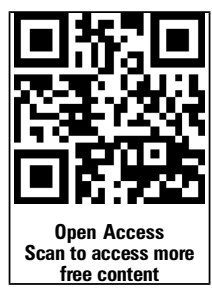

\section{CrossMark}

\section{To cite: Durkin $S$,}

Brennan E, Coomber K,

et al. Tob Control 2015;24 ii26-ii32.

\section{ABSTRACT}

Background Plain packaging (PP) with larger graphic health warnings (GHWs) was implemented in Australia in late 2012. This study examined effects of these packaging changes on short-term changes in quitting-related cognitions and behaviours.

Methods We used a series of cohorts of Australian adult cigarette smokers originally sourced from a nationally representative cross-sectional tracking survey, followed up approximately 1 month after their baseline interview $(n$ (weighted) $=5441)$. Logistic regression analyses compared changes in seven quitting-related outcomes over this 1-month follow-up period for the cohorts surveyed before PP, over the period of transition to $\mathrm{PP}$, and during the first year of $\mathrm{PP}$, adjusting for baseline levels of the outcome and covariates.

Results Compared to the referent group of smokers who completed their follow-up survey pre-PP, those who were followed-up in the early transition period showed significantly greater increases in rates of stopping themselves from smoking $(\mathrm{OR}=1.51,95 \% \mathrm{Cl}(1.08$ to 2.10)) and higher quit attempt rates $(\mathrm{OR}=1.43,95 \% \mathrm{Cl}$ (1.00 to 2.03)), those followed-up in the late transition period showed greater increases in intentions to quit $(\mathrm{OR}=1.42,95 \% \mathrm{Cl}$ (1.06 to 1.92)) and pack concealment $(\mathrm{OR}=1.55,95 \% \mathrm{Cl}(1.05$ to 2.31$))$, and those followedup in the first year of PP showed higher levels of pack concealment $(\mathrm{OR}=1.65,95 \% \mathrm{Cl}$ (1.01 to 2.72)), more premature stubbing out of cigarettes $(\mathrm{OR}=1.55,95 \% \mathrm{Cl}$ (1.01 to 2.36)), and higher quit attempt rates $(\mathrm{OR}=1.52$, $95 \% \mathrm{Cl}(1.01$ to 2.30$)$ ).

Conclusions These findings provide some of the strongest evidence to date that implementation of PP with larger GHWs was associated with increased rates of quitting cognitions, microindicators of concern and quit attempts among adult cigarette smokers.

\section{INTRODUCTION}

Through the introduction in late 2012 of tobacco plain packaging (PP), the Australian government explicitly aimed to: reduce the attractiveness and appeal of tobacco products, particularly among young people; increase the effectiveness of the graphic health warnings (GHWs) on packs; and reduce the ability of the packaging to mislead consumers about the harms of smoking. ${ }^{12}$ Ultimately, through the achievement of these objectives, and as part of a comprehensive suite of tobacco control measures, the government also anticipated that this legislation would contribute to efforts to reduce Australian smoking rates over the longer term. ${ }^{1}{ }^{2}$ At the same time, new and larger GHWs covering $75 \%$ of the front of cigarette packs (up from 30\% previously) and maintaining coverage of $90 \%$ of the back, were also introduced. ${ }^{2}{ }^{3}$ This paper aims to examine the effects of these packaging changes on short-term changes in quitting-related cognitions and behaviours 1 year after the full implementation of this legislation.

Experimental and naturalistic studies have provided some indications that $\mathrm{PP}$ with large GHWs may increase quitting-related cognitions and behaviours. Experimental studies found that compared to fully branded packs, plain packaged cigarettes and packages with fewer branded elements were associated with lower consumer demand and greater self-reported likelihood of quitting among adults, ${ }^{4-8}$ and reduced demand, lower intentions to try smoking and greater cessation behaviour among adolescents. ${ }^{9-11}$ Another recent experimental study using plain packs modelled after those introduced in Australia, found that smokers who had been abstinent for $12 \mathrm{~h}$ and who were randomised to view and then describe a plain pack, subsequently reported lower craving levels than those randomised to view fully branded packs, although after this brief exposure, reported motivation to stop smoking did not differ. ${ }^{12}$

One naturalistic study of young adult smokers who used plain packs for 2 weeks reported reduced consumption, less smoking around others, more thoughts about quitting, more avoidant behaviours such as concealing the pack, and more microindicators of concern such as forgoing cigarettes, than when using fully branded packs. ${ }^{13}$ Another naturalistic study of young adult roll-your-own smokers found that smoking from plain packs with large GHWs for 10 days was associated with greater avoidant behaviours (hiding the pack and not smoking in front of others) and cessation-related thoughts (greater interest in reducing consumption and quitting). ${ }^{14}$

To date, cross-sectional tracking surveys of smokers at the state and national level have demonstrated that implementation of the new Australian packaging reduced the appeal of tobacco products and increased the effectiveness of health warnings 
up to $6^{15}$ and 12 months after implementation, ${ }^{16}$ as well as finding some reduction in the extent to which smokers are misled about the harms of smoking. ${ }^{16}$

Early effects of the implementation of packaging changes in Australia on adult quitting cognitions and behaviours have been indicated in two published studies. A population survey conducted during the transition to the new packaging ${ }^{17}$ found that smokers using plain packs were more likely than those using fully branded packs to have at least daily thoughts about quitting in the past week, and to rate quitting as a higher priority in their life, but did not differ in quitting intentions. A second study examining 'Quitline' calls in the Australian state of New South Wales found, similar to the pattern after the initial introduction of GHWs in 2006, calls increased by $78 \%$, peaking 4 weeks after the start of the transition to the new packaging. Notably though, calls remained elevated for 6 months, a longer time than that observed after the introduction of the 2006 GHWs. ${ }^{18}$

Another study of patrons seated in outdoor areas of cafes, restaurants and bars found that observed rates of active smoking and pack display reduced from preimplementation to postimplementation, ${ }^{19}$ with lower rates maintained 1 year later. ${ }^{20}$ These reductions in active smoking rates could reflect reduced prevalence of population smoking over time, consistent with recently released national survey data, ${ }^{21}$ while another interpretation is that smokers may have chosen to light up less often in public after plain packs were introduced to avoid being judged by others.

Building on this previous work, we used a series of cohorts of Australian adult smokers originally sourced from a nationally representative cross-sectional tracking survey, followed up approximately 1 month after their baseline interview to further examine the effects of the new packaging on quitting-related cognitions and behaviours. We compared change in these outcomes over this 1-month follow-up period for the cohorts surveyed before the packaging changes, over the 2-month period of transition to the new packaging, and during the first year of the new packaging.

\section{METHODS}

\section{Study design and participants}

Between 9 April 2012 and 30 March 2014, 10308 respondents completed a continuous cross-sectional telephone baseline survey (except between 21 December 2012 and 2 January 2013, and 20 December 2013 and 6 January 2014, when the interview centre was closed over the Christmas-New Year period). Telephone interviews were conducted using a dualframe sample design, with half of baseline participants recruited via landline random digit dialling (RDD) and half by mobile phone RDD. Details of sampling methodology are described elsewhere. $^{16} 22$ Respondents were aged 18-69 years and were either smokers ( $\mathrm{n}$ (unweighted) $=8755$ ) or recent quitters (quit in the past 12 months, $\mathrm{n}$ (unweighted) $=1553$ ). Those who smoked daily or weekly were classified as smokers, while those who smoked monthly or less-than-monthly were allowed to selfidentify as a current or ex-smoker.

The mean monthly baseline survey response rate was defined as completed baseline interviews as a proportion of 'estimated in-scope contacts' that could be interviewed within the survey period. This is a conservative assessment of the response rate, to take account of the fact that some households/respondents that refused the screening process would in fact be in-scope (see technical report for detail of calculations ${ }^{22}$ ). The mean monthly baseline survey response rate, adjusted for those who declined to be formally screened, but may have been eligible for the study, was 57\% (range 51-63\%).

All survey participants who agreed to be recontacted were followed up approximately 1 month later (median=29 days, range 18-64 days), thereby creating an ongoing series of 1-month cohort samples. All participants who completed the follow-up had the chance to win one of five $\$ 100$ retail vouchers per month. For the current study, we restricted the sample to baseline current smokers of factory-made or roll-your-own cigarettes (ie, we excluded $\mathrm{n}$ (unweighted) $=158$ cigar, pipe, 'something else' smokers and $n$ (unweighted) $=1553$ recent quitters). Of the eligible baseline cigarette smokers ( $\mathrm{n}$ (unweighted) $=8597$ ), 95\% agreed to be recontacted (n(unweighted) $=8144$ ) and of these, $83 \%$ were successfully recontacted and completed the follow-up survey $(\mathrm{n}$ (unweighted $)=6775)$.

We further restricted the sample to those who completed their follow-up survey before the implementation of the $12.5 \%$ tax increase for tobacco products that occurred in Australia on 1 December 2013 (excluding $\mathrm{n}$ (unweighted)=1288 eligible cigarette smokers who completed follow-up after this date). Limiting the study period in this way allowed us to better isolate the effects of the packaging policy from those of the tax increase. Finally, we also limited the sample to those respondents who provided valid data on all covariates (excluding $\mathrm{n}$ (unweighted) $=61$ cigarette smokers, $<2 \%$ of remaining sample).

This sample of 'baseline cigarette smokers' (n(unweighted) =5426; (weighted) $=5441$ ) was used in analyses predicting quit attempts. For analyses predicting quitting cognitions and microindicators of concern, the sample was restricted to those baseline cigarette smokers who continued to be a cigarette smoker at follow-up ('continuing cigarette smokers'; n(unweighted) $=5145$; (weighted $)=5137$ ), given that these questions were only able to be asked of those who currently smoked.

\section{Outcome measures}

Quitting-related cognitions at follow-up

Substantial research has demonstrated that thoughts about quitting and quit intentions prospectively predict making quit attempts. $^{23-25}$ Frequency of thoughts about quitting was assessed by asking 'During the past week, how often have you thought about quitting?' with response options: 'several times a day'; 'once a day'; 'once every few days'; 'once'; or 'not at all'. Consistent with previous research which found daily thoughts of quitting increased with antismoking advertising, ${ }^{26}$ responses were dichotomised into those who had thought about quitting at least once a day in the past week versus those who had thought about quitting less often. Quit intentions were measured using two questions: 'Do you intend to quit in the next month?' and 'Have you set a firm date to quit in the next month?'

\section{Pack concealment and microindicators of concern at follow-up}

Covering up or concealing cigarette packs, prematurely stubbing out cigarettes in response to thoughts about the harms, and forgoing cigarettes, have all been found to prospectively predict quit attempts over the long-term in population-based studies. ${ }^{27-}$ ${ }^{32}$ Respondents were asked 'In the last month, how often did you deliberately cover up or conceal your pack, or put your cigarettes in another container?', 'In the last month, how often did you stub out a cigarette before you finished it because you thought about the harms of smoking?' and 'In the last month, how often did you stop yourself from having a cigarette when you had an urge to smoke?' For each behaviour, response options were, 'never'; 'once or twice', 'several times' or 'many 
times'. Responses were dichotomised into those who reported the behaviour 'several times' or 'many times' (in the past month) versus those who reported the behaviour less frequently.

\section{Quit attempts at follow-up}

Those who were smoking at baseline were asked at follow-up if they were still smoking and if so, whether they had made any attempts to quit smoking over the past month. We created a binary variable that compared those who had not made a quit attempt between baseline and follow-up, with those who had made a quit attempt and were still smoking at follow-up (ie, made an unsuccessful quit attempt), or were quit at follow-up (ie, made a successful quit attempt). Thus, this variable allowed us to predict the proportion of smokers making quit attempts, irrespective of whether these attempts were successful.

\section{Covariates}

All cohort analyses controlled for sex, age, education and socioeconomic status (measured using a 2011 index of relative disadvantage based on respondents' postcode). ${ }^{33}$ Analyses also controlled for baseline addiction level using the Heaviness of Smoking Index (HSI), ${ }^{34}$ and for past 3-month antismoking advertising activity using Target Audience Rating Points (TARPs, ${ }^{26} 35$ based on date of follow-up interview). Cigarette costliness in the month of follow-up interview was calculated as the ratio of the average recommended retail price (RRP) of the top 10 brands (weighted by market share), to the average weekly earnings in the respondents' state of residence. ${ }^{36}$ We controlled for percentage change in costliness over the past 3 months, in those survey months in which RRPs increased due to excise/customs duty indexation: ${ }^{22}$ percentage change in costliness in August 2012, $\mathrm{M}=-0.00, \mathrm{SE}=0.03$; February 2013, $\mathrm{M}=3.29, \mathrm{SE}=0.05$; August 2013, $\mathrm{M}=0.42, \mathrm{SE}=0.08$. All analyses also controlled for the number of days between the baseline and follow-up surveys, and the date of follow-up interview. Table 1 provides the weighted number of participants within each covariate subgroup and provides associated percentages overall and by each analytic phase.

\section{Weighting}

A baseline design weight and post-stratification weight were used. As detailed elsewhere, the design weight accounted for the probability of each respondent participating in the survey, based on landline or mobile phone usage. ${ }^{22}$ The post-stratification weight accounted for telephony status, and sex, age by education, and state of residence.

The longitudinal weight for the follow-up data (used in these analyses) was derived from an adjustment to the baseline weighting variable. The probability of response to the follow-up survey was modelled for all baseline cases using separate logistic regressions for smokers and recent quitters. The baseline weight was divided by the predicted probability from this regression so that low probability cases were weighted up relative to higher probability cases. Finally, the weights were calibrated to meet the original baseline rim weighting targets for sex, age by education status, and state of residence. ${ }^{22}$

\section{Statistical analysis}

Proportions of those reporting quitting-related cognitions and behaviours in the follow-up survey were compared across four distinct phases. The pre-PP phase included those who completed both baseline (10 April-1 September 2012) and follow-up surveys (7 May 2012-30 September 2012) prior to implementation of the packaging changes (Baseline pre-PP-Follow-up
pre-PP). The early transition phase included those surveyed at baseline in the pre-packaging changes period (20 August-28 September 2012) and followed-up during the transition to the new packaging (1 October-11 November 2012; Baseline pre-PP -Follow-up Transition). The late transition phase included those first surveyed during the transition to the new packaging (1 October-30 November 2012) and followed-up either during the transition or soon after the full implementation of the new packaging (29 October 2012-20 January 2013; Baseline Transition-Follow-up Transition/Early PP). The PP year 1 phase included those who completed both surveys in the first year of full implementation of the new packaging (baseline surveys: 1 December 2012 to 4 November 2013; follow-up surveys: 2 January 2013-30 November 2013; Baseline PP year 1-Follow-up PP year 1). We included each individual's baseline level of each outcome variable as a predictor of that particular outcome variable at follow-up (eg, baseline frequency of quitting thoughts was included as a predictor in the models where follow-up frequency of quitting thoughts was the outcome variable). This enabled the use of the phase variable as a predictor of the variance in follow-up quitting cognitions and behaviour that remained unexplained by an individual's baseline levels. So, in effect the phase variable acted as a predictor of the difference in an individual's quitting cognitions and behaviours between the baseline and follow-up surveys (approximately 1 month apart). In all logistic regression analyses, the pre- $P P$ phase was used as the referent category. We conducted models that were unadjusted and adjusted for covariates. Preliminary logistic regression analyses (unadjusted and adjusted) were first conducted to examine if there were any differences between phases on the baseline levels of each outcome variable (see online supplementary appendix A).

In analyses examining whether PP phase was associated with quit attempts at follow-up, we used the recency of previous quit attempts at baseline as the baseline level of the outcome variable (as described above), given that Partos et $a l^{37}$ found that the recency of previous quit attempts is an important predictor of subsequent quit attempts. We used a modified version of the variable created by Partos et al, ${ }^{37}$ with five categories indicating whether smokers had never previously tried to quit, had tried to quit more than 12 months ago, had tried to quit between six and 12 months ago, had tried to quit 2-6 months ago or had tried to quit within the past month.

Additionally, as previous research indicates that increased quitting cognitions and behaviours can occur in the lead up to tax increases that have been announced ahead of their implementation time, ${ }^{38} 39$ we conducted sensitivity testing to explore effects (in adjusted models) with and without inclusion of data collected in November 2013, the month prior to the tax increase on 1 December 2013. In addition, previous research has indicated that interest in quitting tends to vary in reliable ways in the last 3 weeks of December (less interest, less quitting) and the first 2 weeks of January (more interest, more quitting). ${ }^{40}$ Therefore, we also repeated all adjusted analyses including two indicator variables to capture these seasonality effects.

All analyses were conducted in Stata V.12.1, ${ }^{41}$ adjusting for the effects of sample weighting on parameter estimates and SEs. In addition, an unconditional approach (ie, the 'subpopulation' command in Stata V.12.1) was used to limit the sample as appropriate for each set of analyses, ensuring correct estimation of the SEs. All reported adjusted proportions and ORs were adjusted for age, sex, education, socioeconomic status, HSI, antismoking advertising activity, change in cigarette costliness, number of days between the baseline and follow-up surveys and date of 
Table 1 Weighted number of cases and percentages of demographic and other covariates among continuing smokers (CS) ${ }^{*}$ and among baseline smokers $(\mathrm{BS})^{\dagger}$, overall and by plain packaging phase

\begin{tabular}{|c|c|c|c|c|c|c|c|c|c|c|}
\hline & \multicolumn{2}{|l|}{ Total } & \multicolumn{2}{|l|}{ Pre-PP } & \multicolumn{2}{|c|}{ Early transition } & \multicolumn{2}{|c|}{ Late transition } & \multicolumn{2}{|l|}{ PP year 1} \\
\hline & CS & BS & CS & BS & CS & BS & CS & BS & CS & BS \\
\hline Weighted, $\mathrm{n}$ & 5137 & 5441 & 1339 & 1423 & 254 & 276 & 595 & 617 & 2948 & 3125 \\
\hline \multicolumn{11}{|l|}{ Demographic covariates, \% } \\
\hline \multicolumn{11}{|l|}{ Sex } \\
\hline Males & 54.6 & 54.9 & 55.1 & 55.0 & 53.1 & 54.3 & 53.5 & 54.1 & 54.7 & 55.1 \\
\hline Females & 45.4 & 45.1 & 44.9 & 45.0 & 46.9 & 45.7 & 46.5 & 45.9 & 45.3 & 44.9 \\
\hline \multicolumn{11}{|l|}{ Age } \\
\hline $18-29$ & 27.8 & 28.6 & 29.1 & 30.1 & 25.4 & 27.4 & 28.5 & 28.4 & 27.3 & 28.1 \\
\hline $30-49$ & 45.9 & 45.5 & 43.9 & 43.4 & 46.3 & 45.3 & 46.3 & 46.2 & 46.7 & 46.4 \\
\hline $50-69$ & 26.2 & 25.9 & 26.9 & 26.5 & 28.3 & 27.3 & 25.2 & 25.4 & 25.9 & 25.6 \\
\hline \multicolumn{11}{|l|}{ Education } \\
\hline Less than high school & 33.1 & 32.5 & 30.9 & 30.3 & 29.3 & 29.2 & 38.0 & 37.2 & 33.4 & 32.9 \\
\hline $\begin{array}{l}\text { Completed high school/ } \\
\text { some tertiary }\end{array}$ & 54.5 & 54.7 & 57.0 & 57.2 & 56.8 & 57.8 & 48.4 & 49.5 & 54.4 & 54.3 \\
\hline Tertiary or above & 12.5 & 12.8 & 12.1 & 12.6 & 14.0 & 13.0 & 13.6 & 13.3 & 12.2 & 12.8 \\
\hline \multicolumn{11}{|l|}{ Socio-economic status } \\
\hline Low & 40.2 & 39.9 & 38.5 & 38.4 & 36.4 & 35.8 & 40.0 & 39.2 & 41.4 & 41.0 \\
\hline Mid & 41.8 & 42.0 & 41.7 & 41.2 & 42.8 & 43.9 & 43.1 & 43.2 & 41.6 & 42.0 \\
\hline High & 17.9 & 18.1 & 19.8 & 20.4 & 20.8 & 20.3 & 17.0 & 17.6 & 17.0 & 17.0 \\
\hline \multicolumn{11}{|l|}{ Other covariates, mean (SE) } \\
\hline Heaviness of Smoking Index & $2.19(0.03)$ & $2.13(0.03)$ & $2.17(0.05)$ & $2.09(0.05)$ & $2.22(0.12)$ & $2.14(0.12)$ & $2.08(0.08)$ & $2.06(0.08)$ & $2.23(0.04)$ & $2.17(0.04)$ \\
\hline $\begin{array}{l}\text { Days between baseline and } \\
\text { follow-up }\end{array}$ & $29.92(0.08)$ & $29.97(0.08)$ & $29.15(0.13)$ & $29.19(0.13)$ & $30.03(0.38)$ & $30.45(0.39)$ & $30.80(0.29)$ & $30.80(0.28)$ & $30.08(0.10)$ & $30.11(0.10)$ \\
\hline $\begin{array}{l}\text { Anti-smoking advertising in } \\
\text { past } 3 \text { months }\end{array}$ & $1483(12.8)$ & $1485(12.5)$ & $1662(25.4)$ & $1667(24.5)$ & $1102(56.7)$ & $1125(56.1)$ & $1421(28.2)$ & $1425(27.5)$ & $1447(17.2)$ & $14.46(16.8)$ \\
\hline
\end{tabular}

All data are weighted using longitudinal weights. Due to rounding, Ns may not sum to total and percentages may not sum to 100 . Descriptive data for the covariate capturing percentage change in cigarette costliness is presented in text.

*Eligible sample limited to respondents who were cigarette smokers at baseline and at follow-up. This sample was used in analyses predicting quitting thoughts, intentions, pack concealment, and micro-indicators of concern.

tEligible sample limited to respondents who were cigarette smokers at baseline (i.e., either still smoking or not smoking at follow-up). This sample was used in analyses predicting attempts to quit in the past month.

follow-up survey. In Tables, we present results from the unadjusted and adjusted models. For brevity, we refer only to results from the adjusted models in text.

\section{RESULTS}

\section{Sample characteristics and preliminary analyses}

Table 1 shows the weighted sample at each phase and the characteristics of the sample who were smoking cigarettes at both baseline and follow-up interviews (continuing smokers), and those who were smoking at baseline and either continued to smoke or had quit at follow-up interview (baseline smokers).

Preliminary analyses indicated some significant differences in quitting cognitions and behaviours measured in the baseline cross-sectional surveys between the pre-PP phase and subsequent phases (see online supplementary appendix A). Compared to pre-PP, there was a significantly lower level of baseline daily thoughts of quitting in those surveyed during the late transition and PP year 1 phases. There was also a significantly greater proportion setting a baseline firm date to quit and concealing packs in those surveyed during $P P$ year 1 as compared to pre-PP.

\section{Analyses of the impact of PP on short-term within-person change in quitting cognitions and behaviours}

Table 2 shows that compared to the pre-PP phase there were no significant differences in the proportion of continuing smokers who changed their thoughts about quitting to at-least-daily at follow-up across each subsequent phase. Compared to those surveyed in pre-PP, there were significantly greater increases in the rate of intentions to quit at follow-up during late transition, although the rate returned to baseline levels among continuing smokers during PP year 1. A similar pattern emerged for the proportion of those reporting a firm date to quit within the next month although the difference between those surveyed during pre-PP and late transition was not significant.

Continuing smokers were significantly more likely to report increased follow-up rates of concealing their pack in late transition and PP year 1 compared to pre-PP (table 2). Continuing smokers were also significantly more likely to report increases in stubbing out their cigarette in PP year 1 compared to pre-PP. Continuing smokers surveyed during early transition were significantly more likely to report increased rates of stopping smoking when they had an urge at follow-up as compared to those surveyed in pre-PP.

Importantly, there were significantly greater increases in quit attempt rates in the early transition and $P P$ year 1 phases, as compared to the pre-PP phase (table 2).

Sensitivity testing excluding data from November 2013 and including additional covariates to adjust for seasonal factors showed a similar pattern of effects for all findings (available in online supplementary appendices B and C).

\section{DISCUSSION}

Overall, we found evidence that smokers were more likely to show short-term increases in quitting intentions, and to engage in quitting behaviours after implementation of the packaging changes. After adjusting for important covariates and baseline 
Table 2 Association between plain packaging (PP) phases and follow-up levels of quitting-related cognitions and behaviours-logistic regression results including baseline levels of each outcome variable in all models

\begin{tabular}{|c|c|c|c|c|c|c|c|}
\hline & Weighted N & & & Pre-PP & Early transition & Late transition & PP year 1 \\
\hline Daily thoughts about quitting in the past week $t$ & 5079 & $\begin{array}{l}\text { Unadjusted } \\
\text { Adjusted }\end{array}$ & $\begin{array}{l}\% \\
\text { OR }(95 \% \mathrm{Cl}) \\
\% \\
\text { OR }(95 \% \mathrm{Cl})\end{array}$ & $\begin{array}{l}36.1 \\
1.00 \\
33.2 \\
1.00\end{array}$ & $\begin{array}{l}37.4 \\
1.08 \text { (0.77 to } 1.53) \\
36.2 \\
1.20(0.83 \text { to } 1.73)\end{array}$ & $\begin{array}{l}36.8 \\
1.04(0.81 \text { to } 1.34) \\
36.1 \\
1.20(0.89 \text { to } 1.60)\end{array}$ & $\begin{array}{l}36.6 \\
1.03(0.86 \text { to } 1.23) \\
38.2 \\
1.36(0.90 \text { to } 2.04)\end{array}$ \\
\hline Intend to quit in next montht & 5137 & $\begin{array}{l}\text { Unadjusted } \\
\text { Adjusted }\end{array}$ & $\begin{array}{l}\% \\
\text { OR }(95 \% \mathrm{Cl}) \\
\% \\
\text { OR }(95 \% \mathrm{Cl})\end{array}$ & $\begin{array}{l}34.8 \\
1.00 \\
36.1 \\
1.00\end{array}$ & $\begin{array}{l}35.5 \\
1.04 \text { (0.74 to } 1.47) \\
36.5 \\
1.03 \text { (0.72 to } 1.47)\end{array}$ & $\begin{array}{l}41.7^{* *} \\
1.50(1.16 \text { to } 1.95) \\
42.0^{*} \\
1.42(1.06 \text { to } 1.92)\end{array}$ & $\begin{array}{l}36.3 \\
1.09(0.92 \text { to } 1.30) \\
35.6 \\
0.98(0.64 \text { to } 1.48)\end{array}$ \\
\hline Firm date to quit in next montht & 5137 & $\begin{array}{l}\text { Unadjusted } \\
\text { Adjusted }\end{array}$ & $\begin{array}{l}\% \\
\text { OR }(95 \% \mathrm{Cl}) \\
\% \\
\text { OR }(95 \% \mathrm{Cl})\end{array}$ & $\begin{array}{l}8.4 \\
1.00 \\
8.6 \\
1.00\end{array}$ & $\begin{array}{l}7.1 \\
0.82 \text { (0.48 to } 1.39) \\
7.1 \\
0.80 \text { (0.46 to } 1.39)\end{array}$ & $\begin{array}{l}10.8 \\
1.36(0.92 \text { to } 2.02) \\
11.0 \\
1.35(0.86 \text { to } 2.13)\end{array}$ & $\begin{array}{l}6.6 \\
0.76(0.57 \text { to } 1.00) \\
6.5 \\
0.73(0.36 \text { to } 1.47)\end{array}$ \\
\hline $\begin{array}{l}\text { Concealed or covered pack several or many times } \\
\text { in past montht }\end{array}$ & 5065 & $\begin{array}{l}\text { Unadjusted } \\
\text { Adjusted }\end{array}$ & $\begin{array}{l}\% \\
\text { OR }(95 \% \mathrm{Cl}) \\
\% \\
\text { OR }(95 \% \mathrm{Cl})\end{array}$ & $\begin{array}{l}16.1 \\
1.00 \\
14.3 \\
1.00\end{array}$ & $\begin{array}{l}17.9 \\
1.18(0.78 \text { to } 1.79) \\
16.0 \\
1.19(0.77 \text { to } 1.84)\end{array}$ & $\begin{array}{l}20.0^{*} \\
1.42(1.00 \text { to } 2.02) \\
18.8^{*} \\
1.55(1.05 \text { to } 2.31)\end{array}$ & $\begin{array}{l}18.2 \\
1.22(0.97 \text { to } 1.53) \\
19.5^{*} \\
1.65(1.01 \text { to } 2.72)\end{array}$ \\
\hline Stubbed out several or many times in past month $t$ & 5103 & $\begin{array}{l}\text { Unadjusted } \\
\text { Adjusted }\end{array}$ & $\begin{array}{l}\% \\
\text { OR }(95 \% \mathrm{Cl}) \\
\% \\
\text { OR }(95 \% \mathrm{Cl})\end{array}$ & $\begin{array}{l}24.3 \\
1.00 \\
21.9 \\
1.00\end{array}$ & $\begin{array}{l}23.1 \\
0.92(0.62 \text { to } 1.37) \\
22.2 \\
1.02(0.68 \text { to } 1.54)\end{array}$ & $\begin{array}{l}23.2 \\
0.93(0.70 \text { to } 1.23) \\
22.5 \\
1.04(0.76 \text { to } 1.43)\end{array}$ & $\begin{array}{l}26.9 \\
1.18(0.98 \text { to } 1.43) \\
28.4^{*} \\
1.55 \text { (1.01 to } 2.36)\end{array}$ \\
\hline $\begin{array}{l}\text { Stopped from smoking several or many times } \\
\text { in past montht }\end{array}$ & 5080 & $\begin{array}{l}\text { Unadjusted } \\
\text { Adjusted }\end{array}$ & $\begin{array}{l}\% \\
\text { OR }(95 \% \mathrm{Cl}) \\
\% \\
\text { OR }(95 \% \mathrm{Cl})\end{array}$ & $\begin{array}{l}36.8 \\
1.00 \\
36.7 \\
1.00\end{array}$ & $\begin{array}{l}44.7^{*} \\
1.48 \text { (1.08 to } 2.03) \\
44.9^{*} \\
1.51(1.08 \text { to } 2.10)\end{array}$ & $\begin{array}{l}39.3 \\
1.14(0.89 \text { to } 1.45) \\
39.4 \\
1.15(0.87 \text { to } 1.52)\end{array}$ & $\begin{array}{l}38.2 \\
1.07(0.91 \text { to } 1.26) \\
38.1 \\
1.08(0.74 \text { to } 1.57)\end{array}$ \\
\hline Attempted to quit in past month $\ddagger$ & 5411 & $\begin{array}{l}\text { Unadjusted } \\
\text { Adjusted }\end{array}$ & $\begin{array}{l}\% \\
\text { OR }(95 \% \mathrm{Cl}) \\
\% \\
\text { OR }(95 \% \mathrm{Cl})\end{array}$ & $\begin{array}{l}23.6 \\
1.00 \\
20.2 \\
1.00\end{array}$ & $\begin{array}{l}28.3 \\
1.32 \text { (0.94 to } 1.85) \\
25.5^{*} \\
1.43 \text { (1.00 to } 2.03)\end{array}$ & $\begin{array}{l}18.7^{*} \\
0.71 \text { (0.54 to } 0.95) \\
17.4 \\
0.81 \text { (0.58 to } 1.12)\end{array}$ & $\begin{array}{l}24.1 \\
1.03(0.86 \text { to } 1.23) \\
26.6^{*} \\
1.52(1.01 \text { to } 2.30)\end{array}$ \\
\hline
\end{tabular}

Unadjusted=unadjusted for covariates, adjustment for baseline level of each outcome variable was retained for comparability with adjusted findings. Adjusted=adjusted for baseline level of each outcome variable and covariates: date of the follow-up survey; number of days between baseline and follow-up survey; cumulative Target Audience Rating Points (antismoking television advertising) in the 3 months prior to the follow-up survey; change in cigarette costliness (based on month of follow-up survey); sex; age; education; socioeconomic status; and Heaviness of Smoking Index.

${ }^{*} p<0.05,{ }^{* *} p<0.01$.

†Eligible sample limited to respondents who were cigarette smokers at baseline and at follow-up.

‡Eligible sample limited to respondents who were cigarette smokers at baseline (ie, either still smoking or not smoking at follow-up).

levels of each outcome variable, compared to the pre-PP period, we found greater increases in rates of smokers stopping themselves from smoking when they had an urge to smoke and higher quit attempt rates in the early transition period, and greater intentions to quit in the next month and greater avoidance of GHWs through covering or concealing their pack during the late transition phase. Also, we observed higher levels of pack concealment, more stubbing out of cigarettes prematurely, and higher quit attempt rates in the first full year of the new packaging.

Given the observed reductions in pack appeal and greater GHW effectiveness in cross-sectional surveys by Dunlop et $a l^{15}$ and Wakefield et al, ${ }^{16}$ and the ability of these appeal and GHW effectiveness variables to prospectively predict quitting-related cognitions and behaviours, ${ }^{42}$ it is likely that at least some of the effects observed in this study were driven by changes in these 'upstream' factors more closely tied to the introduction of these policies. The findings from this study support previous experimental and naturalistic studies, ${ }^{8} 1213$ indicating the potential for the packaging changes to influence quitting cognitions, intentions and behaviours. They are also broadly consistent with previous studies demonstrating that larger and more graphic warning labels stimulate greater quitting thoughts, avoidance behaviour, quit intentions and quit attempts. ${ }^{24} 283243$ The findings also accord with studies suggesting these policies had a positive impact on quitting thoughts during the transition phase, ${ }^{17}$ was associated with increased calls to a quitting helpline up to 6 months after the introduction of plain packs, ${ }^{18}$ and was linked to reduced pack display and active smoking at outdoor dining areas immediately following ${ }^{19}$ and around 1 year after implementation. ${ }^{20}$

Results indicated that short-term changes in quit intentions were no different after the full implementation of the new packaging than in the pre-PP phase. The absence of these effects on nextmonth quit intentions and having a firm date to quit, in the presence of effects on microindicators of concern and quit attempts, may indicate that plain packs with larger GHWs continue to trigger increased concern in the smoking moment-reflected in increased stubbing out before finishing a cigarette and pack concealment-but do not continue to increase deliberate plans to quit well after the shock of the transition phase. This would be consistent with previous research that has indicated that larger and stronger GHWs are associated with increased microindicators of concern which in turn prospectively predict quit attempts independent of quit intentions, ${ }^{27-30} 43$ suggesting the presence of a less deliberative pathway of effects. Alternatively, it is also possible that we were unable to detect short-term increases in having a firm date to quit because the baseline levels of such quit intentions were already elevated in those surveyed in the first year after the packaging changes, as revealed by our preliminary analyses of the baseline levels of quitting cognitions and behaviours (see online supplementary appendix A).

The survey used a relatively short follow-up period in order to focus on follow-up quitting cognitions and ensure accurate recall of quit attempts, ${ }^{44}$ and so was not designed or powered to examine quitting success. Therefore, the extent to which the positive outcomes we observed may be maintained and translate 
into longer-term reductions in smoking prevalence still needs to be determined. An additional limitation of this study was that the $P P$ year 1 period had many more participants than the other transition phases, and so it is possible that we were unable to detect small effects in the transition phases, whereas in the final phase we may have had greater ability to detect smaller effects.

Strengths of this study include the examination of these cognitions and behaviours in a national sample with a rigorous sampling method, using consistent questions from prior to after the packaging changes, with good follow-up rates. By adjusting for individual differences and levels of each outcome variable at baseline, we were able to minimise the influence of any month-to-month crosssectional sampling variation and permit a clear examination of the influence of the packaging changes on monthly changes in quitting cognitions and behaviours within the same individuals. Adjustment for the amount of antismoking television advertising and changes in cigarette costliness limited the viability of these interventions as competing explanations for observed effects. Furthermore, the sensitivity testing removing November 2013 from the analyses and including adjustment for the impact of seasonal factors indicated that the observed effects were not unduly influenced by anticipation of the December 2013 preannounced tax increase, nor the Christmas and New Year periods.

The observed effects were generally modest in size. It is not unexpected that changes in these 'downstream' quitting outcomes would be small, as the introduction of the new packaging is one factor among many other personal, interpersonal and external (mass media, policy and tobacco marketing) factors likely to combine to influence individual quitting cognitions and behaviours.. ${ }^{25}{ }^{45-47}$ The overall impact on quitting and smoking prevalence will need to be examined in cohort studies with longer-term follow-up and repeated national surveys using standardised methods. In this respect, there have been some recent promising reductions in smoking prevalence from the latest national Australian household surveys conducted before and after the introduction of the new packaging. ${ }^{21}$ Since reductions in overall smoking rates are driven not only by adult smokers quitting, but by adolescents avoiding taking up smoking, national surveys of schoolchildren will also be important to examine, including in the years to come when more complete quantification of effects might be possible. ${ }^{48}{ }^{49}$ Nonetheless, these data provide some of the strongest evidence to date that implementation of PP and larger GHWs was associated with

\section{What this paper adds}

- Experimental and naturalistic studies suggested that plain packaging with large graphic health warnings may increase quitting-related cognitions and behaviours among adult smokers.

- Australian studies conducted since plain packaging implementation demonstrated reduced appeal of tobacco products, increased effectiveness of health warnings and an increase in Quitline calls.

- This national cohort study of Australian adult cigarette smokers provides evidence that plain packaging with larger graphic health warnings increased rates of quit intentions, pack avoidance, stopping oneself from smoking and quit attempts during the transition period, as well as increased levels of pack avoidance, stubbing out prematurely and quit attempts in the first year of the packaging changes. quitting cognitions, microindicators of concern and increased quit attempts among adult smokers.

Acknowledgements The authors thank Professor Ron Borland for sharing questions from the ITC survey for inclusion in the telephone tracking survey, the Social Research Centre for data collection and Megan Bayly for data checking.

Contributors MW designed the study. $\mathrm{KC}$ and $\mathrm{MZ}$ managed data collection and cleaned data files. SD, EB and KC analysed the data and interpreted the results. SD drafted the manuscript with contributions from all authors. All authors approved the final manuscript.

Funding The National Plain Packaging Tracking Survey was funded under a contract with the Australian Government Department of Health and Ageing.

Competing interests The authors wish to advise that MW was a member and MS a technical writer for the Tobacco Working Group of the Australian National Preventive Health Task Force and MW was a member of the Expert Advisory Committee on Plain Packaging that advised the Australian Department of Health on research pertaining to the plain packaging legislation. MW, SD and EB hold competitive grant funding from the Australian National Health and Medical Research Council and MW holds competitive grant funding from the US National Institutes of Health, Australian National Preventive Health Agency and BUPA Health Foundation.

Ethics approval The survey was approved by the Cancer Council Victoria Human Ethics Committee (HREC 0018).

Provenance and peer review Not commissioned; externally peer reviewed.

Data sharing statement No further data are available.

Open Access This is an Open Access article distributed in accordance with the Creative Commons Attribution Non Commercial (CC BY-NC 4.0) license, which permits others to distribute, remix, adapt, build upon this work non-commercially, and license their derivative works on different terms, provided the original work is properly cited and the use is non-commercial. See: http://creativecommons.org/ licenses/by-nc/4.0/

\section{REFERENCES}

1 Tobacco Plain Packaging Act. No. 148, 2011 as amended. 2011. http://www. comlaw.gov.au/Details/C2013C00190

2 Scollo M, Lindorff K, Coomber K, et al. Standardised packaging and new enlarged graphic health warnings for tobacco products in Australia-legislative requirements and implementation of the Tobacco Plain Packaging Act 2011 and the Competition and Consumer (Tobacco) Information Standard. Tob Control 2015;24:ii9-16.

3 Competition and Consumer (Tobacco) Information Standard. F2013C00598. 2011. http://www.comlaw.gov.au/Details/F2013C00598

4 Thrasher JF, Rousu MC, Hammond D, et al. Estimating the impact of pictorial health warnings and "plain" cigarette packaging: evidence from experimental auctions among adult smokers in the United States. Health Policy 2011;102:41-8.

5 Hoek J, Wong C, Gendall P, et al. Effects of dissuasive packaging on young adult smokers. Tob Control 2011;20:183-8.

6 Hammond D, Doxey J, Daniel S, et al. Impact of female-oriented cigarette packaging in the United States. Nicotine Tob Res 2011;13:579-88.

7 White CM, Hammond D, Thrasher JF, et al. The potential impact of plain packaging of cigarette products among Brazilian young women: an experimental study. BMC Public Health 2012;12:737.

8 Hammond D. Standardized packaging of tobacco products: evidence review. Prepared on behalf of the Irish Department of Health; March 2014. http://www. drugsandalcohol.ie/22106/1/Standardized-Packaging-of-Tobacco-Products-EvidenceReview.pdf (accessed 19 Sep 2014).

9 Hammond D, Daniel S, White CM. The effect of cigarette branding and plain packaging on female youth in the United Kingdom. J Adolesc Health 2013;52:151-7.

10 Rootman I, Flay BR. A study on youth smoking-plain packaging, health warnings, event marketing and price reductions. Toronto: University of Toronto, University of Illinois at Chicago, York University, Ontario, Tobacco Research Unit, Addiction Research Foundation, 1995

11 Kotnowski K, Hammond D, Fong GT, et al. The efficacy of standardized cigarette packaging among young women in Canada: a discrete choice experiment. Seattle, WA: Society for Research on Nicotine \& Tobacco Annual Meeting, 2014.

12 Brose LS, Chong CB, Aspinall E, et al. Effects of standardised cigarette packaging on craving, motivation to stop and perceptions of cigarettes and packs. Psychol Health 2014;29:849-60.

13 Moodie C, Mackintosh AM, Hastings G, et al. Young adult smokers' perceptions of plain packaging: a pilot naturalistic study. Tob Control 2011;20:367-73.

14 Gallopel-Morvan K, Moodie C, Eker F, et al. Perceptions of plain packaging among young adult roll-your-own smokers in France: a naturalistic approach. Tob Control Published Online First: 11 Jun 2014. doi:10.1136/tobaccocontrol-2013-051513

15 Dunlop SM, Dobbins T, Young JM, et al. Impact of Australia's introduction of tobacco plain packs on adult smokers' pack-related perceptions and responses: results from a continuous tracking survey. BMJ Open 2014;4:e005836. 
16 Wakefield M, Coomber K, Zacher M, et al. Australian adult smokers' responses to plain packaging with larger graphic health warnings 1 year after implementation: results from a national cross-sectional tracking survey. Tob Control 2015;24:ii17-25.

17 Wakefield M, Hayes L, Durkin S, et al. Introduction effects of the Australian plain packaging policy on adult smokers: a cross-sectional study. BMJ Open 2013;3:e003175

18 Young JM, Stacey I, Dobbins TA, et al. Association between tobacco plain packaging and Quitline calls: a population-based, interrupted time-series analysis. Med J Aust 2014;200:29-32.

19 Zacher M, Bayly M, Brennan E, et al. Personal tobacco pack display before and after the introduction of plain packaging with larger pictorial health warnings in Australia: an observational study of outdoor café strips. Addiction 2014;109:653-62.

20 Zacher M, Bayly M, Brennan E, et al. Personal pack display and active smoking at outdoor café strips: assessing the impact of plain packaging 1 year postimplementation. Tob Control 2015;24:ii94-7.

21 Australian Institute of Health and Welfare. Highlights from the 2013 survey: tobacco smoking. Canberra: Australian Institute of Health and Welfare, 2014. http://www. aihw.gov.au/alcohol-and-other-drugs/ndshs/ (accessed 19 September 2014).

22 Coomber K, Zacher M, Durkin S, et al. Australian National Tobacco Plain Packaging Tracking Survey: Technical Report. Melbourne: Cancer Council Victoria and Social Research Centre, 2014. http://tobaccocontrol.bmj.com/lookup/suppl/doi:10.1136/ tobaccocontrol-2014-052050/-/DC1.

23 Hyland A, Borland R, Li Q, et al. Individual-level predictors of cessation behaviours among participants in the International Tobacco Control (ITC) Four Country Survey. Tob Control 2006;15:iii83-94.

24 Borland R, Yong HH, Balmford J, et al. Motivational factors predict quit attempts but not maintenance of smoking cessation: findings from the International Tobacco Control Four country project. Nicotine Tob Res 2010;12:S4-11.

25 Vangeli E, Stapleton J, Smit ES, et al. Predictors of attempts to stop smoking and their success in adult general population samples: a systematic review. Addiction 2011;106:2110-21.

26 Dunlop S, Cotter T, Perez D, et al. Televised antismoking advertising: effects of level and duration of exposure. Am J Public Health 2013;103:e66-73.

27 Borland R. Tobacco health warnings and smoking-related cognitions and behaviours. Addiction 1997;92:1427-35.

28 Borland $\mathrm{R}$, Yong $\mathrm{HH}$, Wilson $\mathrm{N}$, et al. How reactions to cigarette packet health warnings influence quitting: findings from the ITC Four-Country survey. Addiction 2009;104:669-75.

29 Partos TR, Borland R, Thrasher JF, et al. The predictive utility of micro indicators of concern about smoking: findings from the International Tobacco Control Four Country study. Addict Behav 2014;39:1235-42.

30 Li L, Borland R, Fong GT, et al. Smoking-related thoughts and microbehaviours, and their predictive power for quitting: findings from the International Tobacco Control (ITC) China Survey. Tob Contro/ Published Online First: 25 Feb 2014. doi:10.1136/ tobaccocontrol-2013-051384

31 Hammond D, Fong GT, McDonald PW, et al. Graphic Canadian cigarette warning labels and adverse outcomes: evidence from Canadian smokers. Am J Public Health 2004;94:1442-5.

32 Yong $\mathrm{H}-\mathrm{H}$, Borland R, Thrasher JF, et al. Mediational pathways of the impact of cigarette warning labels on quit attempts. Health Psychol 2014;33:1410-20.

33 Australian Bureau of Statistics. Technical paper: socio-economic indexes for areas (SEIFA) 2011. Canberra, Australia: Australian Bureau of Statistics, 2013. http://
www.ausstats.abs.gov.au/ausstats/subscriber.nsf/0/22CEDA8038AF7A0DCA257B3 B00116E34/\$File/2033.0.55.001\%20seifa\%202011\%20technical\%20paper.pdf (accessed 19 Sep 2014)

34 Heatherton TF, Kozlowski LT, Frecker RC, et al. Measuring the heaviness of smoking: using self-reported time to the first cigarette of the day and number of cigarettes smoked per day. Br J Addict 1989;84:791-9.

35 Wakefield M, Spittal M, Durkin S, et al. Effects of mass media campaign exposure intensity and durability on quit attempts in a population-based cohort study. Health Educ Res 2011;26:988-97.

36 Australian Bureau of Statistics. Average Weekly Earnings, Australia. Cat No 6302.0. November 2013. http://www.abs.gov.au/ausstats/abs@.nsf/mf/6302.0 (accessed 19 Sep 2014).

37 Partos TR, Borland $\mathrm{R}$, Yong $\mathrm{HH}$, et al. The quitting rollercoaster: how recent quitting history affects future cessation outcomes (data from the International Tobacco Control 4-country cohort study). Nicotine Tob Res 2013;15:1578-87.

38 Harwell TS, Lee L, Haugland C, et al. Utilization of a tobacco quit line prior to and after a tobacco tax increase. J Public Health Manag Pract 2007;13:637-41.

39 Bush T, Zbikowski S, Mahoney L, et al. The 2009 US federal cigarette tax increase and Quitline utilization in 16 states. J Environ Public Health 2012;314740.

40 Durkin S, Wakefield MA, Spittal MJ. Which types of televised anti-tobacco campaigns prompt more quitline calls from disadvantaged groups? Health Educ Res 2011;26:998-1009.

41 StataCorp. Stata Statistical Software: Release 12. College Station, TX: StataCorp LP, 2011

42 Brennan E, Durkin S, Coomber K, et al. Are quitting-related cognitions and behaviours predicted by proximal responses to plain packaging with larger health warnings? Findings from a national cohort study with Australian adult smokers. Tob Control 2015;24:ii33-41.

43 Borland R, Wilson N, Fong GT, et al. Impact of graphic and text warnings on cigarette packs: findings from four countries over five years. Tob Control 2009;18:358-64.

44 Borland R, Partos TR, Yong HH, et al. How much unsuccessful quitting activity is going on among adult smokers? Data from the International Tobacco Control Four Country cohort survey. Addiction 2012;107:673-82.

45 Wakefield MA, Durkin S, Spittal MJ, et al. Impact of tobacco control policies and mass media campaigns on monthly adult smoking prevalence. Am J Public Health 2008;98:1443-50.

46 Zhou X, Nonnemaker J, Sherrill B, et al. Attempts to quit smoking and relapse: factors associated with success or failure from the ATTEMPT cohort study. Addict Behav 2009;34:365-73.

47 Wakefield MA, Coomber K, Durkin SJ, et al. Time series analysis of the impact of tobacco control policies on smoking prevalence among Australian adults, 20012011. Bull World Health Organ 2014;92:413-22.

48 White VM, Warne CD, Spittal MJ, et al. What impact have tobacco control policies, cigarette price and tobacco control programme funding had on Australian adolescents' smoking? Findings over a 15-year period. Addiction 2011;106: 1493-502.

49 White V, Durkin S, Coomber K, et al. What is the role of tobacco control advertising intensity and duration in reducing adolescent smoking prevalence? Findings from 16 -years of tobacco control mass media advertising in Australia. Tob Control Published Online First: 29 Aug 2013. doi:10.1136/tobaccocontrol-2012-050945 